\title{
EFECTO DEL COMPORTAMIENTO TERMO-HIGROMECÁNICO A MACROESCALA DE MADERA BAJO COMPRESIÓN PERPENDICULAR A LA FIBRA EN LAS PROPIEDADES NANOMECÁNICAS DE SU ESTRUCTURA CELULAR
}

\author{
EFFECT OF THERMO-HYGROMECHANICAL BEHAVIOUR AT \\ MACROSCALE OF WOOD UNDER COMPRESSION PERPENDICULAR \\ TO THE GRAIN IN NANOMECHANICAL PROPERTIES OF CELLULAR \\ STRUCTURE
}

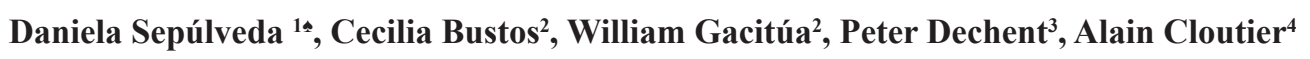

\section{RESUMEN}

El objetivo de este estudio fue evaluar y correlacionar el efecto termo-higromecánico a macroescala de las especies de Pinus radiata D. Don y de Eucalyptus nitens (Deane \& Maiden) con las propiedades nanomecánicas evaluadas en la estructura celular, con el fin de visualizar el comportamiento mecánico de la capa S2 de la pared celular y de la lamela media de probetas bajo compresión perpendicular a la fibra y bajo condiciones ambientales cíclicas, considerando como caso, los puentes de tableros tensados. A macroescala, se estudiaron 4 probetas sin tratamiento preservante para ambas especies y 4 probetas de Pinus radiata tratadas con creosota. Las propiedades nanomecánicas de la estructura celular de la madera fueron determinadas por medio de nanoindentaciones. Los resultados mostraron que el módulo de elasticidad y la dureza de la estructura celular de las maderas sometidas a variaciones termohigromecánicasen el tiempo y a condiciones de tensado, aumentaron significativamente en el verano del segundo ciclo que con respecto al invierno del primer ciclo. Por otro lado, se evidenció que el tensado de las probetas originó una reducción del módulo de elasticidad y de la dureza así como también un incremento del factor de relajación de la estructura celular de la madera con respecto la madera sin tensado, expuestas a deformación libre.

Palabras claves: Propiedades mecánicas, estructura celular, nanoindentaciones, Pinus radiata, Eucalyptus nitens, tableros tensado.

\begin{abstract}
The objective of this study was to evaluate and correlate at macroscale the thermo-hygromechanical effect of on the nanomechanical properties of Pinus radiata D. Don and Eucalyptus nitens(Deane \& Maiden)evaluated in the S2 layer of the cell wall and in the middle lamella of specimens under compression perpendicular to grain and under cyclic environmental conditions. At macroscale, 4 stresslaminated deck specimens without preservative treatment were studied for both species and 4 deck specimens of radiata pine treated with creosote. The nanomechanical properties of the cellular structure were determined using nanoindentations. The results showed that the thermo-hygromechanical effect at macroscale induced a significant increase of elastic modulus and hardness of the cellular structure during the summer season and during the second environmental cycle, with respect to the winter season

\footnotetext{
Estudiante de Magíster en Ciencia y Tecnología de la Madera, Universidad del Bío-Bío. Concepción, Chile

2 Profesor Asociado, Ph.D., Centro de Biomateriales y Nanotecnología (CBN), Departamento de Ingeniería en Maderas,

Universidad del Bío-Bío. Concepción, Chile

3 Profesor Asociado, Departamento de Ingeniería Civil. Universidad de Concepción. Concepción, Chile

${ }^{4}$ Profesor Ttitular, Ph.D., Centre de Recherche sur le Bois, Université Laval. Québec, Canada.

-Autor para correspondencia: cbustos@ubiobio.cl

Recibido: 26.12.2011 Aceptado: 13.10.2012
} 
and the first cycle. On the other hand, it was shown that the application of long-term compressive loads lead to a significant decrease of the elastic modulus and hardness of the cellular structure of wood and an increase in the relaxation factor, compared to the pieces submitted to free deformation.

Keywords: Mechanical properties, cellular structure, nanoindentations, Pinus radiata, Eucalyptus nitens, stress-laminated deck.

\section{INTRODUCCIÓN}

Las estructuras de madera en servicio se ven afectadas por los esfuerzos mecánicos combinados con variaciones de la humedad y temperatura. El tipo de especie o la aplicación de preservantes en la madera, también contribuyen en su comportamiento estructural (Zhou et al. 1999). La madera bajo esfuerzos mecánicos constantes presenta en un comienzo una deformación lineal elástica, luego desarrolla una deformación adicional en el tiempo conocida como creep (Bodig y Jayne 1993, Guitard 1987). Cuando esta deformación se ve influenciada por la acción conjunta de temperatura y humedad se habla de creep termo-higromecánico. Algunos estudios han sido realizados en este sentido y los resultados han demostrado que las deformaciones en la madera, como resultado del creep higromecánico, son de 5 a 10 veces la deformación inicial elástica (Entwistle y Zadoroshnyj 2008, Svensson y Toratti 2002, Toratti y Svensson 2000). Otras investigaciones determinaron que el creep viscoelástico depende de la acumulación de creep higromecánico, estableciendo una interacción entre ambos fenómenos (Montero et al. 2010, Navi et al. 2002). A diferencia, si un desplazamiento es aplicado instantáneamente y permanece constante, se produce el fenómeno de relajación, descrito como la disminución de la fuerza necesaria para mantener un estado de deformación constante (Bodig y Jayne 1993). La relajación se rige por las mismas características tiempo-dependientes del creep. Según lo informado por Wanbing y Erickson (1994), el comportamiento higromecánico se origina por la migración de las moléculas de agua en la pared celular para alcanzar un nuevo estado de equilibrio en la humedad, puesto que la aplicación de esfuerzos mecánicos en la madera altera el potencial químico existente en ellas. Quenneville y Van Dalen (1994) observaron que bajo carga, los niveles de tensado en la madera disminuyen cuando la madera se expone a una reducción de la humedad relativa. De manera análoga, la madera sometida a incrementos de la temperatura durante un periodo de tiempo, presenta un aumento de la movilidad molecular y por lo tanto, se producen fenómenos higrotérmicos que son importantes de considerar en la reología de la madera. Kainz y Ritter (1998), en su estudio de las variaciones de la temperatura en los puentes de tableros tensados de madera, señalan que éstos presentan un comportamiento termo-higromecánico, determinando disminuciones en los niveles de tensado cuando la madera ha alcanzado temperaturas bajo $0^{\circ} \mathrm{C}$. Del mismo modo, Iida et al. (2002) reportaron que la madera presenta fenómenos de relajación bajo variaciones en la temperatura, siendo más notorio este efecto con descensos en la temperatura que con incrementos de ella.

Las deformaciones higromecánicas en la madera bajo carga constante y bajo múltiples ciclos de humedad son altamente significativas y dependientes de la magnitud del cambio de humedad, y son levemente más altas en compresión que en tracción (Svensson y Toratti 2002, Toratti y Svensson 2000, Wanbing y Erickson 1994). El incremento de la deformación, producto del efecto de ciclos de humedad, es resultado a nivel molecular de la ruptura y formación continua de enlaces de hidrógeno, puesto que durante los procesos de adsorción y desorción, los enlaces de hidrógeno se ven influenciados por las cargas aplicadas y por lo tanto, se forman cada vez en un lugar diferente al situado inicialmente (Navi et al. 2002).

El comportamiento mecánico de la madera se considera como viscoelástico y se fundamenta en que la madera tiene como componentes principales la celulosa y la lignina. La celulosa contribuye a las propiedades de resistencia de las fibras de madera, debido a su estructura cristalina altamente organizada que le otorga un comportamiento elástico (Salmén 2004). De las capas componentes de la pared celular 
secundaria (S1, S2 y S3), la capa S2 es la más dominante, con un 70 a $80 \%$ de espesor, de modo que su estructura microfibrilar gobierna las propiedades mecánicas de las fibras de madera (Salmén 1982). Por otro lado, la lignina es de alta viscosidad y como compuesto cementante de la pared celular se encuentra proporcional y preferentemente en la lamela media (Diaz-vaz 2003). El comportamiento físico y mecánico de la capa S2 en la pared celular y de la lamela media, podría facilitar al entendimiento del comportamiento mecánico de una pieza de madera a nivel celular y a nivel de macroescala. La determinación de las propiedades nanomecánicas de la estructura celular se realiza por medio de la técnica de nanoindentación, donde se registra la profundidad de penetración y la carga aplicada, determinando el módulo de elasticidad, dureza y factor de relajación, entre otros (Fischer-Cripps 2004). Diversos estudios se han realizado en este sentido, nano caracterizando principalmente la capa S2 y la lamela media de las células de la madera, de manera tal de correlacionarlas con otras variables para una mejor caracterización del comportamiento de la estructura celular (Wu et al. 2009, Salmén 2004, Gindl et al. 2004). Por su parte, Moon et al. (2009) relacionaron la dureza en Pinus radiata a nivel macro con la dureza medida en la pared celular. Los autores determinaron que la dureza medida a través de nanoindentaciones es 5 veces mayor que la dureza medida por macroindentación, reafirmando el aporte de la pared celular a las propiedades mecánicas a macro escala.

Es relevante conocer y comprender aspectos que tienen relación con las propiedades ortotrópicas de la madera y su interacción con el entorno, de manera tal que sirva de apoyo para predecir su comportamiento durante su utilización en estructuras mayores. Un ejemplo de aplicación estructural en madera que se ha estado desarrollando en Chile durante los últimos 10 años, son los puentes de tableros tensados (Giuliano et al. 2002). El sistema constructivo de éstos se basa en tablones dispuestos de canto en la dirección longitudinal del puente, los que en conjunto son tensados en la dirección transversal por medio de barras de acero de alta resistencia con un sistema de anclaje en los bordes laterales con placas de acero. La principal problemática de este tipo de estructuras es su pérdida de capacidad de carga en el tiempo producida por pérdidas y/o aumentos del tensado de las barras, debido a la respuesta que muestra la madera al estar sometida a compresión permanente y a condiciones ambientales variables. No obstante lo anterior, las variaciones del tensado de un tablero pueden ser controladas a través de retensados (Ritter 1990).

El objetivo de este estudio fue evaluar y correlacionar el efecto termo-higromecánico en madera de Pinus radiata y Eucalyptus nitens bajo compresión perpendicular a la fibra con las propiedades nanomecánicas de su estructura celular (capa S2 y lamela media).

\section{MATERIALES Y MÉTODOS}

\section{Materiales}

Se utilizó madera de Pinus radiata clasificada estructuralmente como C24 de acuerdo a la norma BS EN 338, 2003, cuya densidad básica fue de $433 \mathrm{~kg} / \mathrm{m}^{3}$ y $12 \%$ de contenido de humedad promedio. Un grupo de muestras de esta especie fue tratado con creosota a $140 \mathrm{~kg} / \mathrm{m}^{3}$ de retención promedio y otro grupo se dejó sin tratamiento preservante como control. Por otro lado, también se utilizó madera de Eucalyptus nitens, sin tratamiento preservante, por su característica de madera refractaria. Esta especie se obtuvo de la zona de Yungay en la VIII Región. La densidad básica promedio de ésta fue de $484 \mathrm{~kg} /$ $\mathrm{m}^{3}$ y el contenido de humedad promedio de $15 \%$.

\section{Armado de probetas}

Las probetas de tablero tensado fueron armadas con 8 tablones de $0.041 \times 0.141 \times 0.2 \mathrm{~m}^{3}$, dispuestos uno sobre otro por las caras de las piezas. Cada tablón fue identificado como A, B, C y D, para registrar la posición relativa de éstos con respecto del borde de la probeta (Figura 1). Las probetas fueron tensadas en dirección normal a la fibra por medio de barras de acero, con una presión interlaminar máxima de 
$2 \mathrm{MPa}$, utilizando un sistema de anclaje en los bordes laterales con placas de acero para mantener la fuerza en las barras de tensado. El historial de carga de cada probeta fue monitoreado mediante el uso de celdas de carga. Se armaron 4 probetas por cada tratamiento, según la especie y tipo de preservante (Tabla 1). La muestra control para cada tratamiento corresponde a un tablón de madera, con las mismas dimensiones de $0.041 \times 0.141 \times 0.2 \mathrm{~m}^{3}$, que estuvo expuesto al mismo acondicionamiento ambiental dentro de la cámara de clima y que no estuvo bajo esfuerzos de compresión.

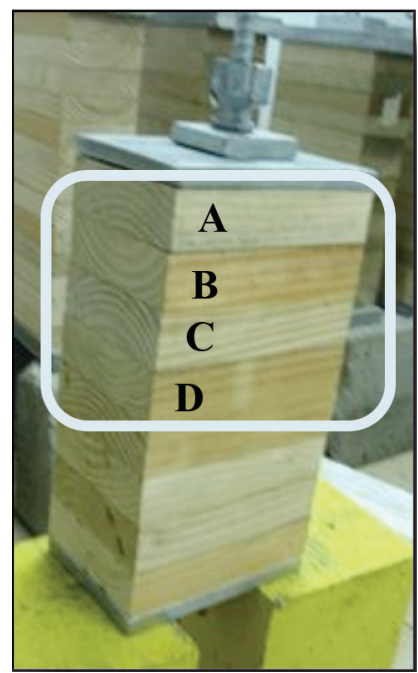

Figura 1. Identificación de la posición de los tablones de Pinus radiata que constituyen la probeta de tablero tensado.

Tabla 1. Tratamientos para las probetas de tablero tensado utilizadas para el análisis del comportamiento termo-higromecánico.

\begin{tabular}{|c|c|c|c|}
\hline $\mathrm{N}^{0}$ Probetas & $\mathrm{N}^{\mathrm{o}}$ Tratamiento & Especie & Preservante \\
\hline 4 & Tratamiento 1 & Eucalyptus nitens & Sin tratar \\
\hline 4 & Tratamiento 2 & Pinus radiata & Creosota \\
\hline 4 & Tratamiento 3 & Pinus radiata & Sin tratar \\
\hline
\end{tabular}

\section{Condiciones ambientales cíclicas de las probetas en cámara de clima}

Las probetas de tablero tensado fueron armadas dentro de una cámara de clima de dimensiones $4.6 \mathrm{x}$ $4.8 \mathrm{~m}^{2}$ del laboratorio de estructuras de la Universidad de Concepción y fueron sometidas a condiciones ambientales cíclicas durante 310 días.

Las probetas fueron expuestas a condiciones secas (verano) establecidas a $20^{\circ} \mathrm{C}$ y $67 \%$ de humedad relativa (HR) y a condiciones húmedas (invierno) a $5^{\circ} \mathrm{C}$ y $88 \%$ de $\mathrm{HR}$, respectivamente (Figura 2). Las condiciones higrotérmicas utilizadas en este estudio, fueron aquellas típicas de invierno y verano de la zona de Coyhaique en la XI región de Chile, las que fueron determinadas de acuerdo a Gallegos (2009), quién evaluó las condiciones ambientales de esta región basadas en datos estadísticos de 5 años, dado el interés de instalar puentes de tablero tensado en esta zona, las cuales fueron reproducidas en laboratorio. Todas las probetas fueron sometidas a ciclos secos y húmedos por 90, 30, 60, 30, 30, 30 y 30 días de acondicionamiento respectivamente. La longitud del primer ciclo fue mayor debido a la estabilización de la cámara de clima. Mientras que la mayor duración del tercer ciclo se debió principalmente al terremoto que afectó a Chile en esa época. 
La temperatura al interior de la madera fue registrada mediante la inserción de termocuplas en el centro de los tablones.

\section{Preparación de las muestras para la determinación de las propiedades nanomecánicas}

Una vez estabilizadas las condiciones en la cámara de clima, se procedió a evaluar las propiedades nanomecánicas de la estructura celular, para ello, se obtuvo muestras al final de cada temporada de los ciclos 1 y 2 (Figura 2) por cada tratamiento utilizado en las probetas (Tabla 1). Las probetas de tablero tensado fueron desarmadas al interior de la cámara de clima para mantener las condiciones ambientales estables en la madera. Para las evaluaciones de las propiedades nanomecánicas, se consideró el elemento de volumen representativo de cada probeta (Sepúlveda et al. 2012), localizado en la madera de primavera del anillo de crecimiento más alejado a la médula en la sección transversal del tablón central D (Figura 1).

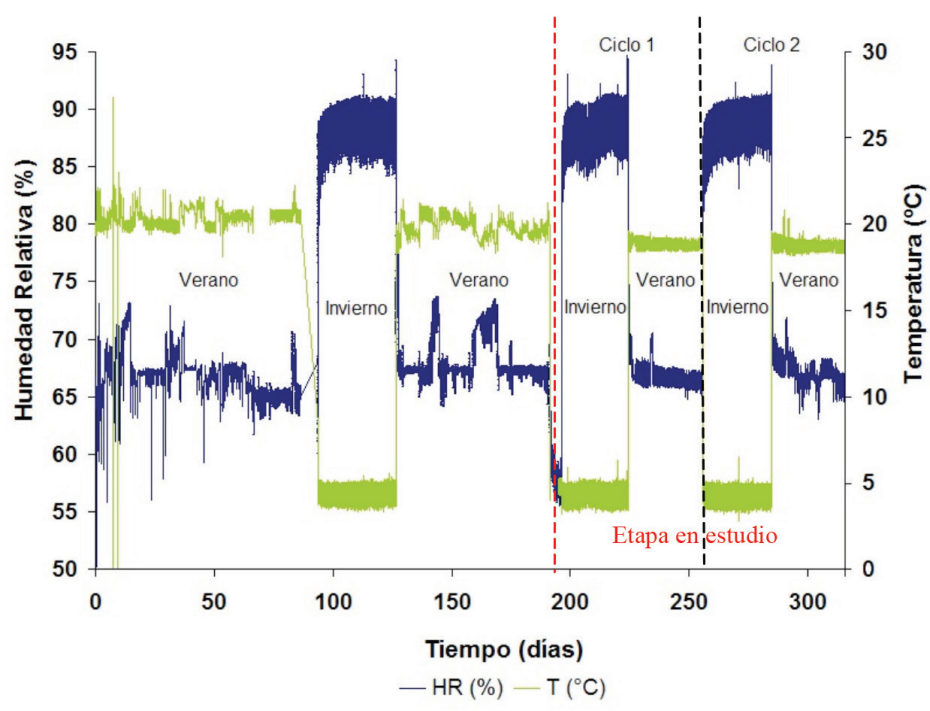

Figura 2. Historial de condiciones ambientales en cámara de clima durante 310 días, indicando la etapa en estudio.

De cada pieza se cortaron listones de $1 \times 1 \mathrm{~cm}^{2}$. Luego con cuchillos de acero de ultrafilo se prepararon cubos de $3 \mathrm{~mm}$ por lado. Los cubos fueron llevados a condición anhídra y fueron impregnados con resina epóxica para otorgar soporte mecánico a la estructura celular. Con un micrótomo se dejó la superficie transversal libre de rugosidades, para ello se trabajó con un cuchillo de vidrio y luego con uno de diamante. Finalmente, las muestras fueron dispuestas en una placa metálica para la medición de sus propiedades nanomecánicas.

\section{Propiedades nanomécanicas}

Para examinar el efecto termo-higromecánico de la madera a macroescala en la estructura celular, se caracterizó el módulo de elasticidad $\left(E_{s}\right)$, la dureza $(\mathrm{H})$ y el factor de relajación en la capa S2 de la pared celular secundaria y en la lamela media, a través de nanoindentaciones, utilizando un nanoindentador TriboIndenter TI-900 marca Hysitron, con una punta de diamante tipo Cube Corner. La figura 3 muestra los ciclos de carga y profundidad empleados en las nanoindentaciones. 
(a)

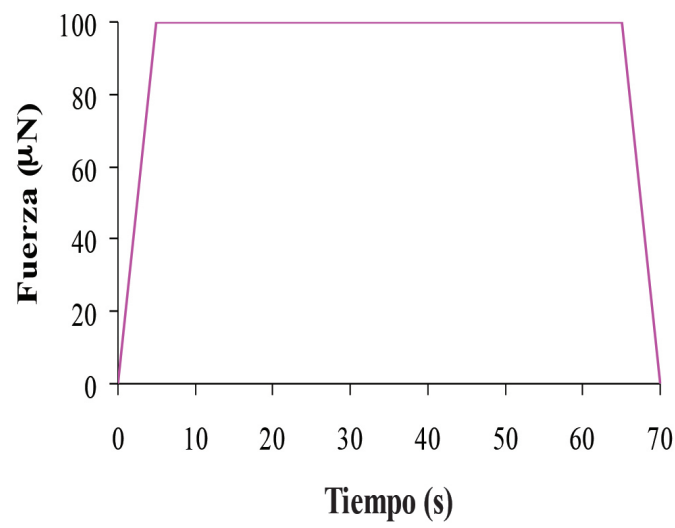

(b)

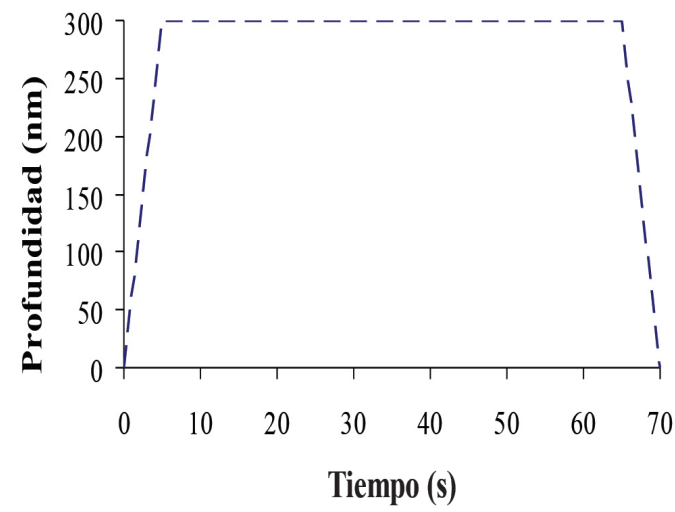

Figura 3. Ciclos utilizados en las nanoindentaciones bajo (a) fuerza constante $\left(E_{s}\right.$ y $\left.\mathrm{H}\right)$ y (b) profundidad constante (Factor de relajación).

El módulo de elasticidad se determinó con la expresión (1) (Fischer-Cripps 2004):

$$
E_{s}=\left(1-v_{s}^{2}\right)\left(\frac{1}{E_{r}}-\frac{1-v_{i}^{2}}{E_{i}}\right)^{-1}
$$

El módulo de elasticidad de la punta de diamante $\left(E_{i}\right)$ es igual a $1140 \mathrm{GPa}$ con una razón de Poisson de 0.07. El módulo de elasticidad reducido $\left(E_{r}\right)$ fue obtenido directamente del ensayo. Se consideró una razón de Poisson igual a 0.3 para las muestras de Pinus radiata y Eucalyptus nitens (Salmén 2004).

La dureza se obtuvo del ensayo a través de la siguiente expresión:

$$
H=\frac{P_{\max }}{A_{h c}}
$$

donde $P_{\max }$ es la carga máxima de indentación y $A_{h c}$ es el área de contacto proyectada, que es una función de la profundidad de contacto.

El factor de relajación $R$ fue expresado en porcentaje mediante la expresión:

$$
R=\frac{F_{1}-F_{2}}{F_{1}} \cdot 100
$$

donde $F_{1}$ es la fuerza para alcanzar la profundidad de la indentación y $F_{2}$ es la fuerza posterior de haber mantenido la profundidad de la indentación constante (Fischer-Cripps 2004). Las nanoindentaciones se realizaron en una superficie de $10 \times 10 \mu \mathrm{m}^{2}$ y de $20 \times 20 \mu \mathrm{m}^{2}$, en muestras de Eucalyptus nitens y Pinus radiata, respectivamente, con un mínimo de 8 nanoindentaciones en la pared celular y 5 en la lamela media. 


\section{Análisis estadístico}

Para el análisis de los resultados se efectuó un análisis de varianza (ANOVA) de cuatro factores para evaluar el efecto del tratamiento, carga inicial, ciclo y temporada (Tabla 2), en las propiedades nanomecánicas de la estructura celular. Se consideraron como pseudorepeticiones al número de nanoindentaciones efectuadas en las muestras con un nivel de significancia $\alpha=0.01$. Para el análisis de los resultados, se utilizó el procedimiento GLM del programa SAS ajustado a modelos lineales generales. No fue necesaria la transformación de la variable dependiente, ya que se cumplió con los supuestos de normalidad y de homogeneidad de varianza. Las comparaciones pareadas se realizaron mediante el test protected Fisher LSD.

Tabla 2. Diseño experimental general utilizado en el análisis del comportamiento termo-

higromecánico de madera comprimida transversalmente.

\begin{tabular}{ccl}
\hline Variables & Niveles & Observación \\
\hline Tratamiento & 3 & $\begin{array}{l}\text { Eucalyptus nitens sin tratamiento preservante: EN s/p } \\
\text { Pinus radiata tratado con creosota: PR c/creosota } \\
\text { Pinus radiata } \text { sin tratamiento preservante: PR s/p }\end{array}$ \\
\hline $\begin{array}{c}\text { Carga inicial } \\
\text { máxima (MPa) }\end{array}$ & 2 & $\begin{array}{l}\text { 0: Tablón control } \\
\text { 2: Probeta de tablero tensado }\end{array}$ \\
\hline Ciclo & 2 & $\begin{array}{l}\text { Ciclo 1 } \\
\text { Ciclo 2 }\end{array}$ \\
\hline Temporada & 2 & $\begin{array}{l}\text { Invierno } \\
\text { Verano }\end{array}$ \\
\hline
\end{tabular}

\section{RESULTADOS Y DISCUSIÓN}

\section{Historiales de carga}

La figura 4 muestra los historiales de carga promedio obtenidos en las probetas de tablero tensado, durante 310 días. Las probetas fueron comprimidas inicialmente a $0.78 \mathrm{MPa}$ y luego retensadas 2 veces al mismo nivel de carga inicial $(0.78 \mathrm{MPa})$ a los 7 y 28 días del armado de éstas, con el fin de evitar inicialmente fuertes variaciones de los niveles de compresión (Ritter 1990). El último retensado fue realizado después de 65 días, con una carga de compresión de $2 \mathrm{MPa}$. Este nivel de carga pretendió simular el nivel de compresión que se aplica en los bordes de anclaje en los puentes de tableros tensados (Ugalde 2004). Las curvas de compresión fueron directamente proporcionales con la humedad relativa e inversamente proporcionales con la temperatura (Figuras 2 y 4). En general, en verano los niveles de compresión disminuyeron con respecto a la carga inicial de tensado y se incrementaron en invierno. Este fenómeno podría atribuirse a la higroscopicidad de la madera. En verano el contenido de humedad promedio en la madera fue $13 \%$ y en temporada de invierno fue de $15 \%$. Un comportamiento similar se reflejó en estudios para las especies de Pseudotsuga menziesii y de Pinus sylvestris, que fueron sometidas a compresión perpendicular y a cambios cíclicos de humedad, presentando una disminución de los niveles de compresión cuando la madera fue expuesta a una reducción de la humedad relativa (Svensson y Toratti 2002, Quenneville y Van Dalen 1994). Se observó una disminución acelerada de la compresión en las probetas de los tres tratamientos, cuando se pasó de verano a invierno, atribuyéndose al cambio inmediato de la temperatura en el interior de la madera, desde $17^{\circ} \mathrm{C}$ al final de la temporada de verano, hasta $4.5^{\circ} \mathrm{C}$ al comienzo de la temporada de invierno. Este efecto se vio aminorado a medida que transcurrió el tiempo, puesto que la humedad retomó su influencia. 


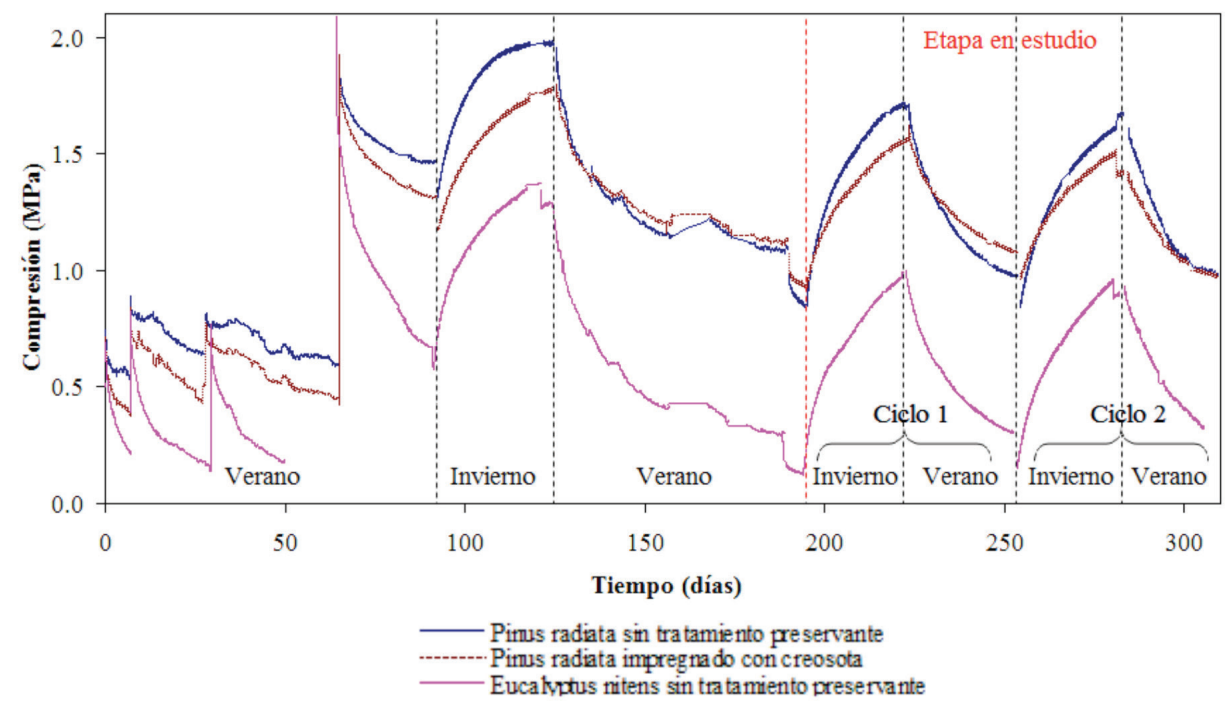

Figura 4. Historial de carga promedio de las probetas de tablero tensado sometidas a compresión perpendicular y a condiciones ambientales cíclicas durante 310 días.

Los niveles máximos de compresión alcanzados durante el segundo ciclo ambiental fueron levemente menores, entre un 2 y $7 \%$, a los obtenidos durante el primer ciclo. Esto podría reflejar una relajación de los esfuerzos de compresión en el tiempo, puesto que la compresión necesaria para alcanzar el estado de deformación inicial durante la temporada de invierno, disminuye con cada ciclo.

Las probetas de Pinus radiata, tratadas con creosota y aquellas sin tratamiento preservante, mostraron un nivel de compresión promedio de 1.3 MPa y las probetas de Eucalyptus nitens presentaron 0.7 MPa. Las probetas de Eucalyptus nitens exhibieron una mayor relajación de la compresión con respecto a las probetas de Pinus radiata con y sin tratamiento. Esta relación coincide con lo establecido por Zhou et al. (1999), puesto que bajo variaciones cíclicas del contendido de humedad entre 11 y 19\%, los autores determinaron en 3 especies de latifoliadas (Paulownia tomentosa, Fagus crenata, Quercus acutissima) un incremento en la deformación higromecánica hasta 3 veces la deformación inicial, mientras que en 3 especies de coníferas (Cryptomerica japonica, Chamaecyparis obtusa, Larix Leptolepis) ésta sólo aumentó en un $50 \%$ respecto a la deformación inicial.

\section{Módulo de Elasticidad obtenido por nanoindentaciones}

En general, los valores del módulo de elasticidad $\left(E_{\mathrm{s}}\right)$ en la pared celular fluctuaron entre 8 y $16 \mathrm{GPa}$, para todos los tratamientos bajo condiciones ambientales variables. El ANOVA mostró interacciones de tercer orden entre Tratamiento*Ciclo*Temporada $(\mathrm{p}<0.0001)$ y entre Tratamiento*Carga inicial ${ }^{*}$ Ciclo $(\mathrm{p}=0.0032)$. Durante el primer ciclo, los resultados mostraron un aumento significativo de $E_{s}$ en la pared celular durante el verano en comparación con el invierno, con un incremento promedio de $1.9 \mathrm{GPa}$ para el Pinus radiata sin tratar y de 4 GPa para el Pinus radiata tratado con creosota. Sin embargo, en el segundo ciclo, no se evidenciaron diferencias significativas entre verano e invierno. En Eucalyptus nitens, sólo se evidenció un aumento de $E_{s}$ de $2.1 \mathrm{GPa}$ en la temporada de verano durante el segundo ciclo. Estos incrementos de $E_{s}$ se atribuyeron a una reducción promedio del $3 \%$ en el contenido de humedad y a un aumento de $12.5^{\circ} \mathrm{C}$ en la temperatura al interior de la madera durante el verano, con respecto al invierno. Dinwoodie (2000) y Wolcott y Shutler (2003), confirmaron un aumento de $E_{s}$ con la disminución del contenido de humedad en la madera, afirmando en el estudio del efecto de humedad y temperatura en álamo amarillo y en espuma de poliuretano, que la respuesta elástica de la madera se incrementa con el aumento de la temperatura. 
El ANOVA no mostró diferencias significativas de $E_{s}$ entre los ciclos ambientales en verano. No obstante, si hubo diferencias significativas en temporada de invierno, donde $E_{s}$ aumentó significativamente en el segundo ciclo al compararlo con el primer ciclo, con un incremento promedio de $3.3 \mathrm{GPa}$ entre las muestras de Pinus radiata. Navi et al. (2002), en su estudio del comportamiento higromecánico de madera de Pinus pinaster, señalaron que la respuesta elástica incrementa tras varios cambios cíclicos del contenido de humedad.

La figura 5 muestra los valores de $E_{s}$ obtenidos en la pared celular como promedio entre las probetas comprimidas y el tablón control, para los tres tratamientos respecto de las temporadas y ciclos ambientales. Durante el primer invierno, $E_{s}$ fue significativamente mayor en la pared celular del Pinus radiata y del Eucalyptus nitens sin tratamiento preservante que en el Pinus radiata tratado con creosota, contrariamente a lo observado en el primer verano. Paralelamente, durante el invierno y verano del segundo ciclo $E_{s}$ fue mayor en las muestras de Pinus radiata con y sin creosota $\left(E_{\text {sprom }}=14 \mathrm{GPa}\right)$, que en muestras de Eucalyptus nitens $\left(E_{\text {sprom }}=13 \mathrm{GPa}\right)$.

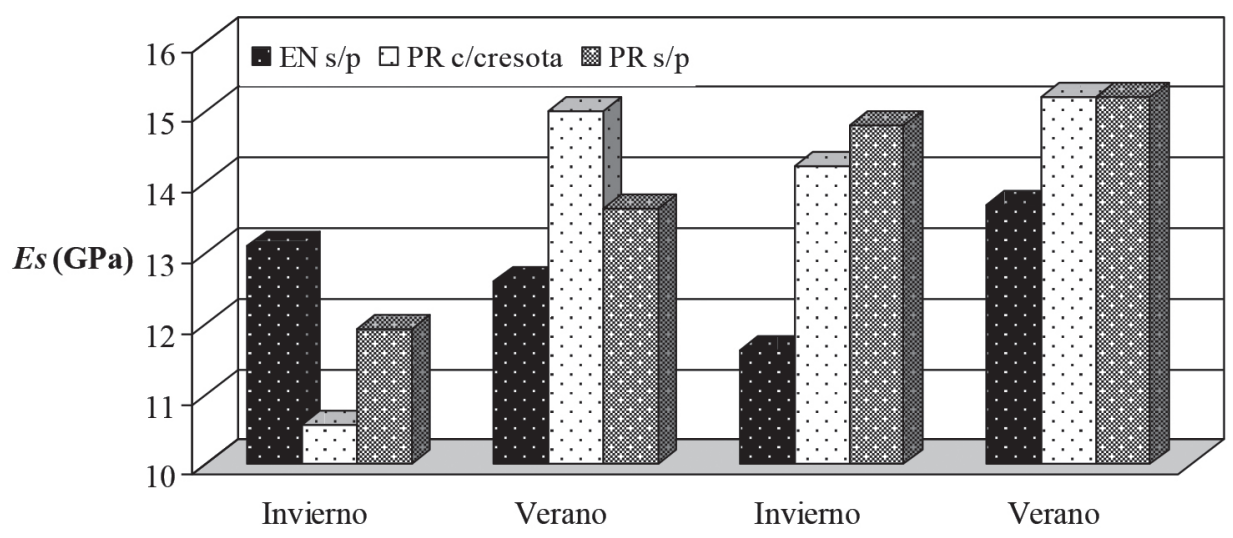

Ciclo 1

Condición ambiental

Ciclo 2

Figura 5. Valores de $E_{\mathrm{s}}$ en la pared celular promedio entre las probetas comprimidas y el tablón control para los tres tratamientos bajo condiciones ambientales variables

(EN s/p: Eucalyptus nitens sin tratamiento preservante. PR c/creosota: Pinus radiata tratado con creosota.

PR s/p: Pinus radiata sin tratamiento preservante).

La figura 6 muestra los valores de $E_{s}$ obtenidos en la pared celular del tablón control y de la probeta de tablero tensado para los tres tratamientos durante los ciclos 1 y 2 . En general, durante el primer ciclo, $E_{s}$ fue $18 \%$ mayor para el tablón control que en la probeta de tablero tensado para cada tratamiento, con la excepción del Pinus radiata tratado con creosota, que mostró un $14 \%$ de disminución. Durante el segundo ciclo no se observaron diferencias significativas entre el tablón control y la probeta comprimida de cada tratamiento. Al parecer, la pared celular en probetas sometidas a compresión mostraría una reducción en su resistencia mecánica, respecto del tablón control que no estuvo sometido a esfuerzos de compresión.

Los valores de $E_{s}$ en la lamela media para los distintos tratamientos bajo condiciones ambientales variables, fluctuaron entre 5 y $9 \mathrm{GPa}$, alcanzando valores más bajos que los obtenidos en la pared celular. El ANOVA evidenció una interacción de tercer orden entre Tratamiento*Ciclo*Temporada $(\mathrm{p}=0.0002)$. 


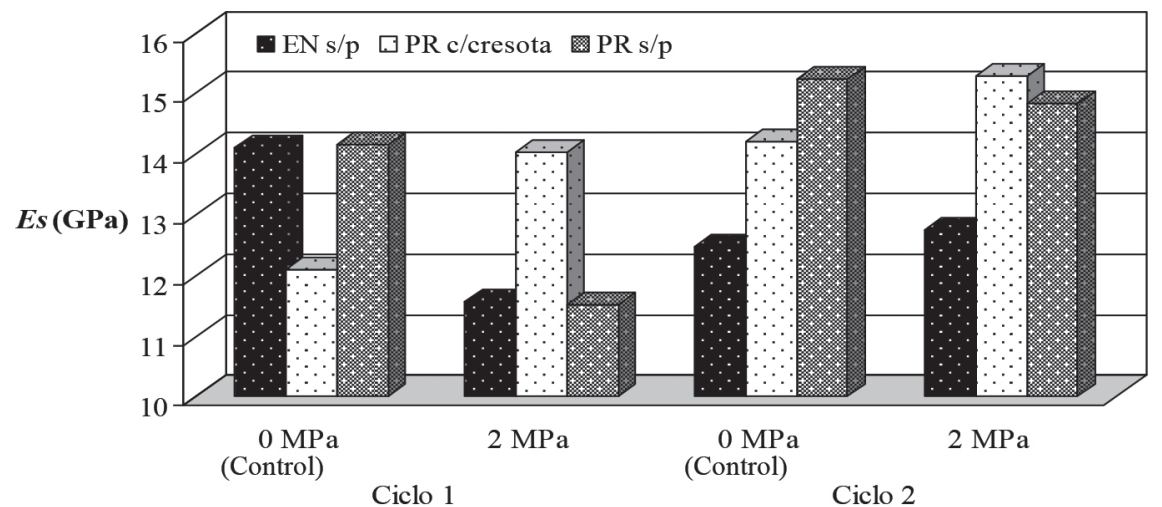

Ciclo 1

Ciclo - Carga incial

Figura 6. Valores de $E_{s}$ en la pared celular de tres tratamientos respecto al nivel de carga inicial durante dos ciclos de condiciones ambientales

(EN s/p: Eucalyptus nitens sin tratamiento preservante. PR c/creosota: Pinus radiata tratado con creosota. PR s/p: Pinus radiata $\sin$ tratamiento preservante).

El módulo de elasticidad en la lamela media de Pinus radiata en la temporada de verano aumentó 1.6 GPa respecto al invierno durante el primer ciclo en muestras tratadas con creosota y en las sin tratamiento de creosota, incrementó $0.7 \mathrm{GPa}$. Este aumento de $E_{s}$ en verano podría asociarse a la reducción de los niveles de compresión observados durante esta temporada en las probetas de tablero tensado de Pinus radiata. Con respecto a los ciclos ambientales, los tratamientos para Pinus radiata mostraron un aumento significativo de $E_{s}$ en la lamela media durante el invierno del segundo ciclo en comparación al primero, con incrementos de 1.5 y 1 GPa en Pinus radiata tratado con creosota y sin tratar, respectivamente (Figura 7). Por otro lado, el módulo de elasticidad en la lamela media de Eucalyptus nitens fue significativamente mayor que en Pinus radiata, con valores promedio de 8.7 y 7.2 GPa, respectivamente. No hubo diferencias significativas del $E_{s}$ de la lamela media entre de madera de Pinus radiata tratada con creosota que con respecto a la sin tratar.

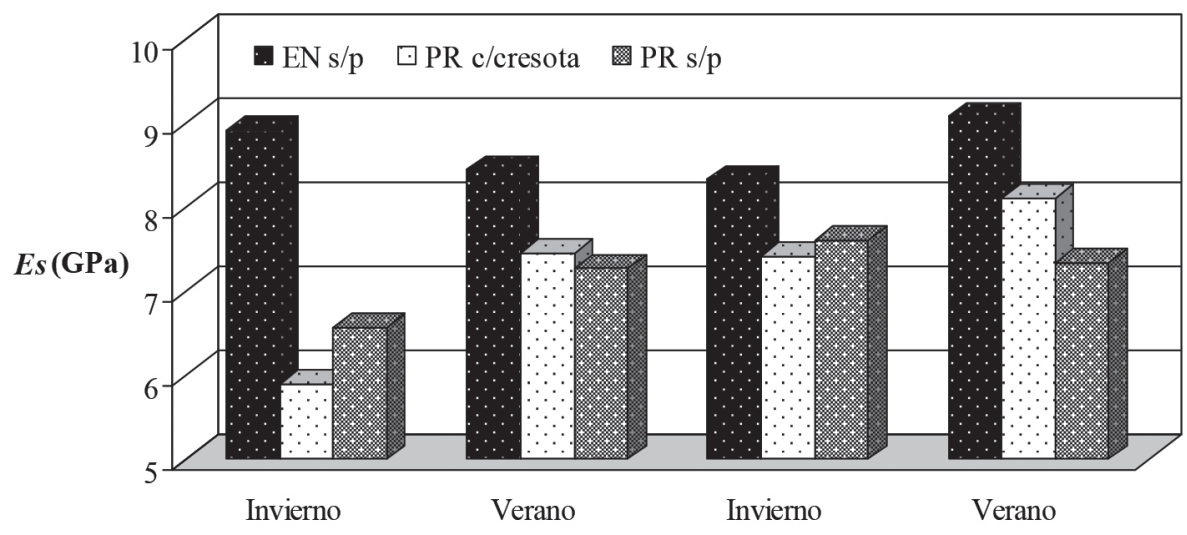

Ciclo 1

\section{Condición ambiental}

Ciclo 2

Figura 7. Valores de $E_{s}$ en la lamela media promedio entre las probetas comprimidas y el tablón control para los tres tratamientos bajo condiciones ambientales variables

(EN s/p: Eucalyptus nitens sin tratamiento preservante. PR c/creosota: Pinus radiata tratado con creosota.

PRs/p: Pinus radiata sin tratamiento preservante). 


\section{Dureza obtenida por nanoindentaciones}

En general, la dureza $(\mathrm{H})$ medida en la pared celular para los distintos tratamientos bajo condiciones ambientales variables, fluctuó entre 0.24 y $0.40 \mathrm{GPa}$. El ANOVA, mostró interacciones de tercer orden entre Tratamiento*Ciclo*Temporada $(\mathrm{p}<0.0001)$ y entre Tratamiento*Carga inicial*Ciclo $(\mathrm{p}<0.0001)$. Los resultados de estos análisis mostraron una mayor dureza en la pared celular en verano que en invierno, con un incremento del $10 \%$ para el Pinus radiata tratado con creosota durante el verano del primer ciclo y con un aumento de 7.6\% para el Pinus radiata sin tratar durante el segundo ciclo (Figura 8). El aumento de la dureza en verano se relacionó inversamente con el contenido de humedad, dado que la madera se expuso a una reducción en $2 \%$ en el contenido de humedad desde la temporada de invierno a la de verano. Esto coincide con lo establecido por Wang y Wang (1999), en su estudio del efecto del contenido de humedad en la dureza a macroescala de 3 especies de coníferas y 3 de latifoliadas. Los autores reportaron que con una disminución del $1 \%$ en el contenido de humedad, la dureza se incrementó en 2.2 y $2.5 \%$ en coníferas y en latifoliadas, respectivamente.

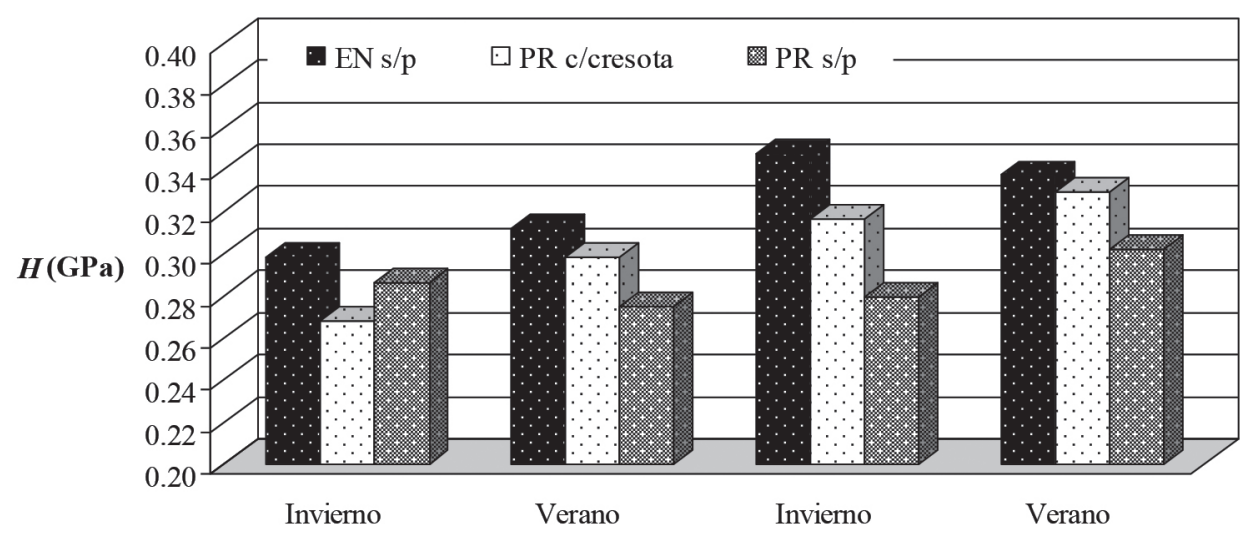

Ciclo 1 Condición ambiental Ciclo 2

Figura 8. Valores de $\mathrm{H}$ en la pared celular promedio entre las probetas comprimidas y el tablón control para los tres tratamientos bajo condiciones ambientales variables

(EN s/p: Eucalyptus nitens sin tratamiento preservante. PR c/creosota: Pinus radiata tratado con creosota.

PR s/p: Pinus radiata sin tratamiento preservante).

En general, la dureza en la pared celular de Eucalyptus nitens fue un 11\% mayor que la dureza en Pinus radiata. Estos resultados reafirman la mayor dureza que caracteriza al Eucalyptus nitens respecto al Pinus radiata. Con respecto a los ciclos ambientales, durante el segundo ciclo, tanto en invierno como en verano, la dureza en la pared celular de los tres tratamientos, aumentó en promedio un $12 \%$. Ishimaru et al. (2001) sugirieron que el incremento de las propiedades mecánicas en la madera tras haber pasado por varios cambios cíclicos de humedad, estaría asociado a una reorientación de las cadenas moleculares de las componentes de la madera, puesto que éstas intentan alcanzar una estabilidad en estos procesos.

La figura 9 muestra los valores de la dureza en la pared celular del tablón control y de la probeta de tablero tensado de los tres tratamientos durante los ciclos 1 y 2 . Estos valores fueron significativamente mayor para el tablón control que en la probeta de tablero tensado. Navi y Heger (2005) señalaron que la aplicación de cargas de compresión perpendicular bajo cambios cíclicos de las condiciones ambientales origina un aplastamiento celular, y que por lo tanto, se produce una disminución en la resistencia mecánica. Esto explicaría la disminución de la dureza en la pared celular de las probetas comprimidas, en comparación al tablón control sin la aplicación de cargas mecánicas. 


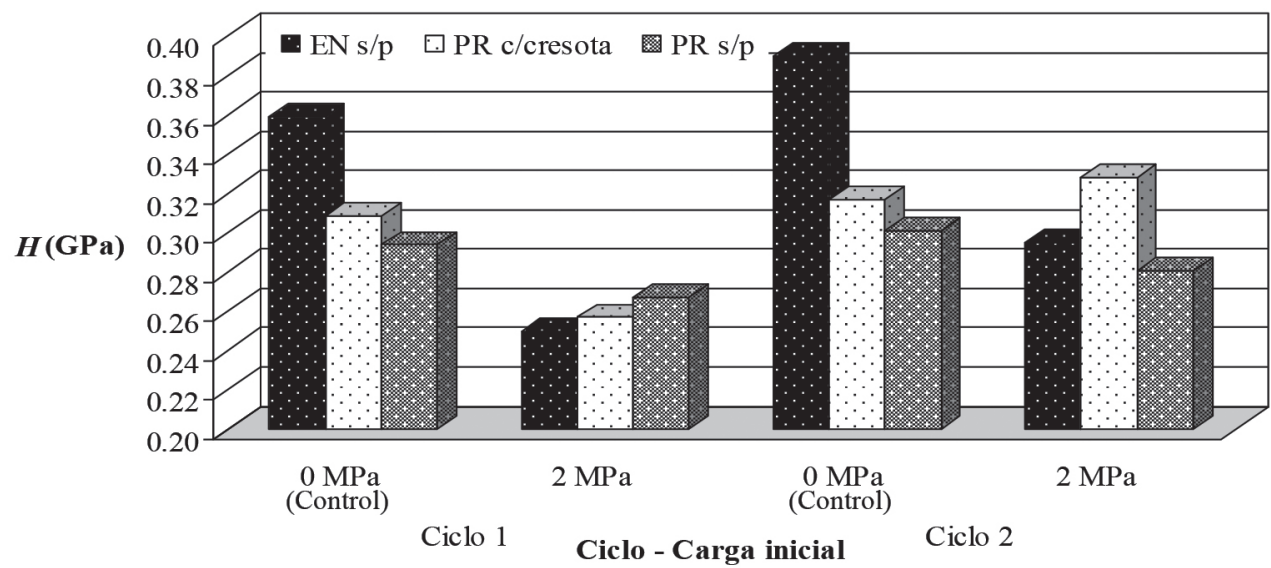

Figura 9. Valores de $\mathrm{H}$ en la pared celular de tres tratamientos respecto al nivel de carga inicial durante dos ciclos de condiciones ambientales.

(EN s/p: Eucalyptus nitens sin tratamiento preservante. PR c/creosota: Pinus radiata tratado con creosota. PR s/p: Pinus radiata sin tratamiento preservante).

Los valores de dureza en lamela media para los distintos tratamientos bajo condiciones ambientales variables fluctuaron entre 0.33 y $0.42 \mathrm{GPa}$. El ANOVA mostró una interacción de tercer orden entre Tratamiento*Ciclo*Temporada $(\mathrm{p}=0.0057)$ y una interacción de segundo orden entre Carga inicial*Temporada $(p=0.0067)$. La Figura 10 ilustra los valores de $\mathrm{H}$ en la lamela media como promedio entre las probetas comprimidas y el tablón control para los tres tratamientos respecto de las temporadas y ciclos ambientales. Ninguno de los tratamientos exhibió diferencias significativas entre la temporada de verano y de invierno en cada ciclo, salvo en Eucalyptus nitens del primer ciclo, que mostró mayor dureza en la lamela media en invierno que en verano, con un valor de $0.4 \mathrm{GPa}$.

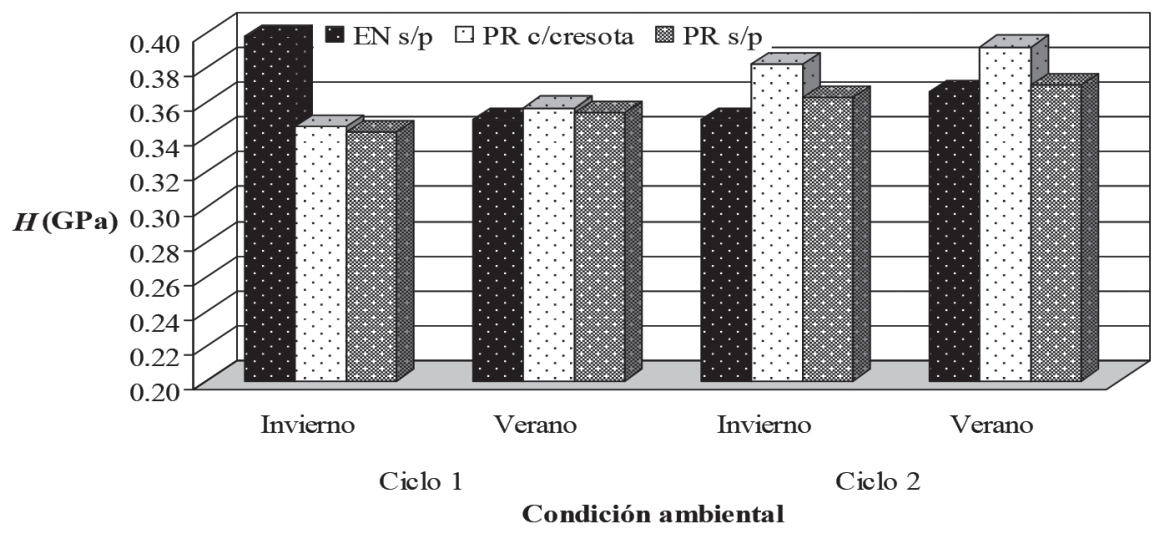

Figura 10. Valores de $\mathrm{H}$ en la lamela media promedio entre las probetas comprimidas y el tablón control para los tres tratamientos bajo condiciones ambientales variables

(EN s/p: Eucalyptus nitens sin tratamiento preservante. PR c/creosota: Pinus radiata tratado con creosota PR s/p: Pinus radiata sin tratamiento preservante). 
La dureza en la lamela media aumentó significativamente en un 9\% durante el segundo ciclo para Pinus radiata tratado con creosota en relación al primer ciclo ambiental. Sin embargo, en Pinus radiata sin tratamiento preservante, la dureza no se vio afectada por las temporadas de invierno y de verano, ni mostró diferencias significativas entre los ciclos ambientales, presentando un valor promedio de 0.36 $\mathrm{GPa}$. Este valor fue superior a la dureza medida en la pared celular para este mismo tratamiento, con $0.29 \mathrm{GPa}$, estableciéndose que la lamela media es más rígida por su origen plástico, en relación a la pared celular, con un comportamiento más elástico (Diaz-vaz 2003).

En promedio entre todos los tratamientos y entre ambos ciclos ambientales, la $\mathrm{H}$ en la lamela media en verano fue mayor para el tablón control $\left(\mathrm{H}_{\text {prom }}=0.38 \mathrm{GPa}\right)$ que en las probetas comprimidas $\left(\mathrm{H}_{\text {prom }}=0.35 \mathrm{GPa}\right)$. En invierno, no hubo diferencias significativas.

\section{Factor de relajación obtenido por nanoindentaciones}

Los valores del factor de relajación en la pared celular fluctuaron entre un 38\% y 54\% para los distintos tratamientos a condiciones ambientales variables. El ANOVA mostró interacciones de tercer orden entre Tratamiento*Carga inicial*Temporada $(\mathrm{p}=0.0055)$ y entre Tratamiento*Carga inicial*Ciclo $(\mathrm{p}=0.0013)$. El factor de relajación tuvo un aumento significativo en la probeta de tablero tensado de Pinus radiata tratado con creosota durante el primer invierno respecto del tablón control, con valores de 50 y 39\%, respectivamente. En Eucalyptus nitens esta diferencia estuvo entre 48 y $41 \%$ durante el segundo verano. Por otro lado, las diferencias entre las temporadas de invierno y de verano no fueron significativas para cada combinación de tratamiento y carga inicial. Por lo tanto, se podría afirmar que el factor de relajación medido en la pared celular no está influenciado por las condiciones ambientales.

Es más notorio el efecto de la aplicación de cargas de compresión respecto del control. De acuerdo al historial de carga de las probetas de tablero tensado, los cambios de las condiciones ambientales implican variaciones en los niveles de compresión, sin embargo, estas variaciones serían muy bajas para producir un efecto en la relajación de la pared celular.

El tratamiento con creosota en madera de Pinus radiata reflejó una reducción en el promedio del factor de relajación de la pared celular de aproximadamente un 9\% respecto al Pinus radiata sin tratamiento, durante gran parte del tiempo del estudio, salvo en el último verano.

La figura 11 muestra los valores del factor de relajación en la pared celular del tablón control y de la probeta de tablero tensado para cada tratamiento, en promedio entre las temporadas durante los ciclos 1 y 2 . Únicamente las paredes celulares de la probeta de tablero tensado de Pinus radiata tratada con creosota mostró que el factor de relajación fue significativamente mayor durante el primer ciclo, con un valor de 50\%, en relación a 44\% durante el segundo ciclo. El factor de relajación en la pared celular de Pinus radiata sin tratamiento preservante no se vio afectado por la aplicación de cargas de compresión, ni mostró diferencias significativas bajo diferentes ciclos termo-higromecánicos, presentando un valor promedio de $48 \%$.De acuerdo a lo anteriormente expuesto, esto podría evidenciar que la relajación producida en las paredes celulares de la madera podría estar influenciada por la creosota presente en las células de la madera. 


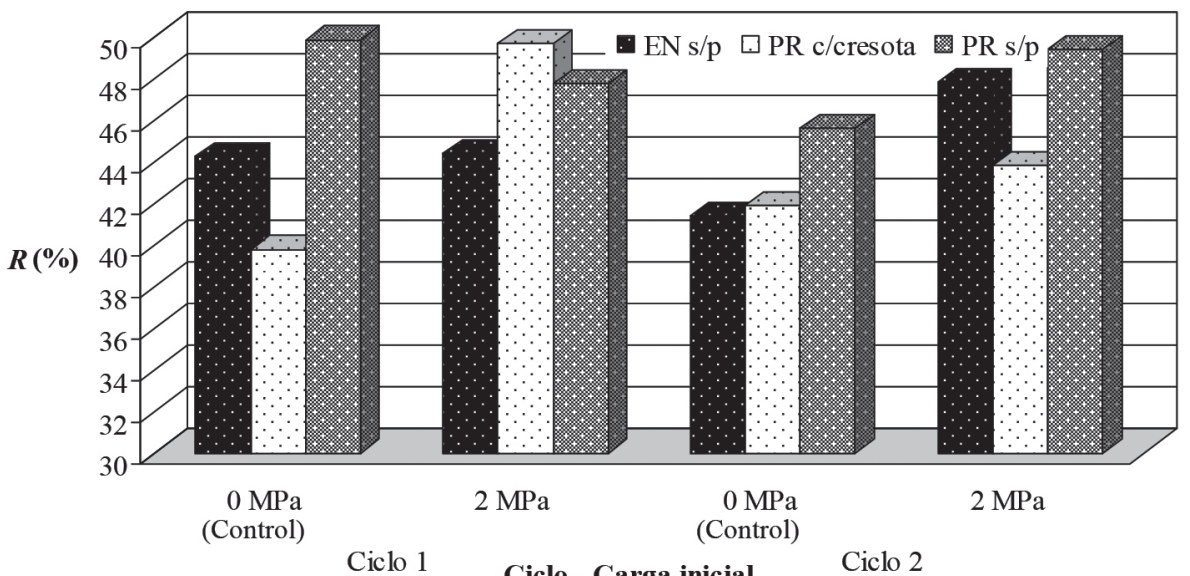

Figura 11. Valores del factor de relajación (R) en la pared celular de tres tratamientos respecto al nivel de carga inicial durante dos ciclos de condiciones ambientales

(EN s/p: Eucalyptus nitens sin tratamiento preservante. PR c/creosota: Pinus radiata tratado con creosota.

PR s/p: Pinus radiata $\sin$ tratamiento preservante).

Por otro lado, los resultados del factor de relajación en la lamela media, para los distintos tratamientos bajo condiciones ambientales variables, fluctuaron entre 36 y 49\%. El ANOVA mostró interacciones de tercer orden entre Tratamiento*Carga inicial*Temporada $(\mathrm{p}=0.0014)$ y entre Tratamiento* Carga inicial*Ciclo $(\mathrm{p}=0.0059)$. En las probetas comprimidas $(2 \mathrm{MPa})$ se produjo un aumento en $5 \%$ en la lamela media del Pinus radiata tratado con creosota, durante la temporada de invierno en relación al verano, y una reducción de 4\% para el Pinus radiata sin tratar (Figura 12).

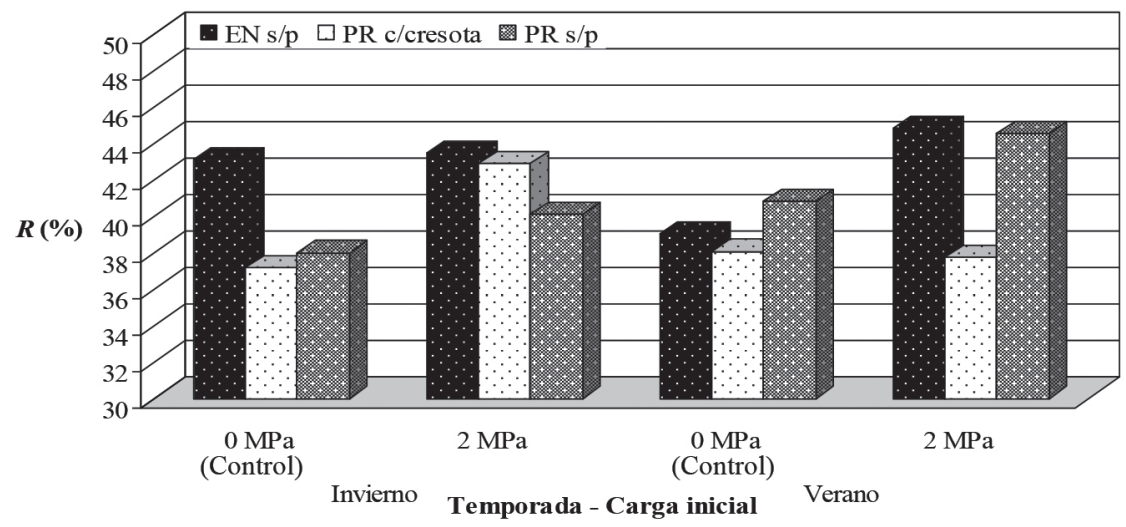

Figura 12. Valores del factor de relajación (R) en la lamela media de tres tratamientos respecto al nivel de carga inicial durante las temporadas de invierno y verano

(EN s/p: Eucalyptus nitens sin tratamiento preservante. PR c/creosota: Pinus radiata tratado con creosota.

PR s/p: Pinus radiata sin tratamiento preservante). 
El factor de relajación en la lamela media de células de madera de Pinus radiata $\sin$ tratar fue mayor en aquella que estuvo tensada que en las sin tensar durante el primer verano, con valores de 49 y $40 \%$, respectivamente. En Eucalyptus nitens, se produjo un efecto similar, alcanzando valores de 49 y $41 \%$. Este resultado evidenciaría que la estructura celular en madera que fue sometida a cargas de compresión tiende a relajar más en comparación a piezas de madera sin tensado.

La figura 13 muestra los valores del factor de relajación en la lamela media del tablón control y de la probeta de tablero tensado para los tres tratamientos en promedio entre las temporadas durante los ciclos 1 y 2. Las diferencias entre ambos ciclos no fueron significativas, con la excepción de la probeta de tablero tensado de Pinus radiata sin tratar, que mostró una disminución durante el segundo ciclo respecto del primero, desde $45 \%$ a $39 \%$, respectivamente.

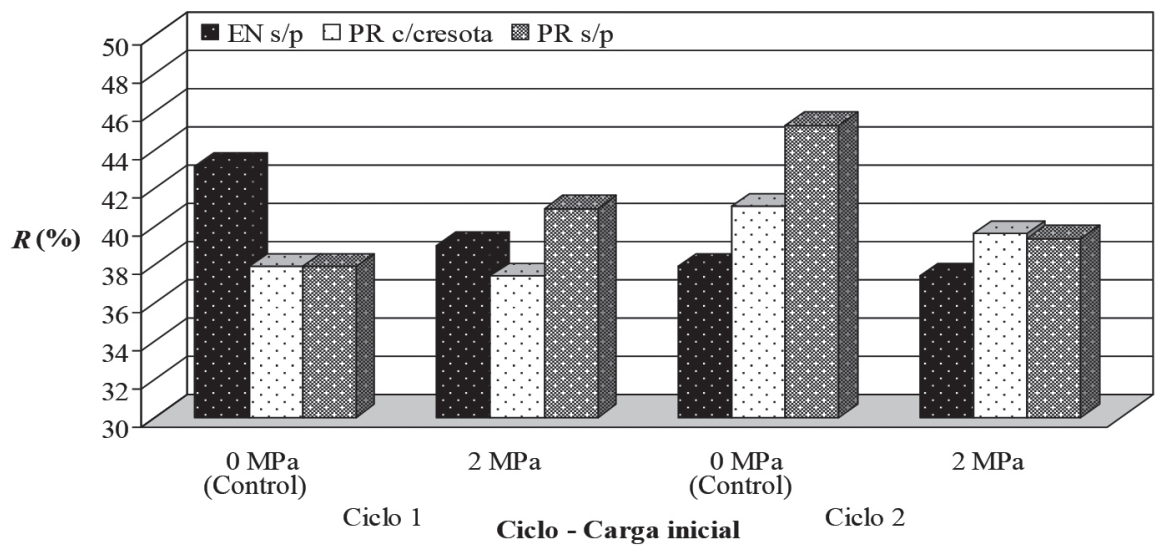

Figura 13. Valores del factor de relajación $(\mathrm{R})$ en la lamela media de tres tratamientos respecto al nivel de carga inicial durante dos ciclos de condiciones ambientales

(EN s/p: Eucalyptus nitens sin tratamiento preservante. PR c/creosota: Pinus radiata tratado con creosota.

PR s/p: Pinus radiata sin tratamiento preservante).

En consecuencia, el comportamiento termo-higromecánico de las probetas de tablero tensado afectó las propiedades mecánicas medidas a nivel celular. Principalmente, disminuciones de los niveles de compresión en un 30\% de la carga inicial en las probetas comprimidas en verano, manifestaron incrementos del $E_{s}$ y $\mathrm{H}$ en la pared celular y la lamela media. Resultado similar se produjo entre el segundo y primer ciclo ambiental. Además, los esfuerzos de compresión aplicados en las probetas, produjeron una disminución del $E_{s} \mathrm{y} \mathrm{H}, \mathrm{y}$ un aumento del factor de relajación de la estructura celular, comparado con el tablón control. 


\section{CONCLUSIONES}

En este estudio se evaluó y se correlacionó el efecto del comportamiento termo-higromecánico de probetas de tablero tensado de Pinus radiata y Eucalyptus nitens con las propiedades nanomecánicas de la estructura celular mediante ensayos de nanoindentaciones. Las probetas de tablero tensado evidenciaron un comportamiento termo-higromecánico, puesto que los niveles de compresión en ellas fueron notoriamente afectados por los cambios de las condiciones ambientales. En invierno, los niveles de compresión aumentaron y en verano, decrecieron. Las probetas de Pinus radiata mostraron niveles de compresión más altos que las probetas de Eucalyptus nitens. La ocurrencia de grietas y de colapso presentadas en la madera de Eucalyptus nitens no permite visualizar a esta especie como apta para el uso en tableros tensados para puentes de madera. El efecto de acoplamiento de la temperatura y humedad relativa del ambiente en el tiempo con la aplicación de cargas de compresión, afectaron directamente las propiedades de la estructura celular, lo que se tradujo en un aumento significativo del módulo de elasticidad y de la dureza en la estructura celular. La aplicación de cargas de compresión a largo plazo produjo una reducción del módulo de elasticidad y de la dureza, y un incremento en el factor de relajación de la estructura celular de la madera, en relación de piezas expuestas a deformación libre. El uso de creosota en madera de Pinus radiata mostró un efecto en el factor de relajación de las paredes celulares, sobretodo en las muestras bajo compresión perpendicular. Por otra parte, las paredes celulares, presentaron mayor módulo de elasticidad, menor dureza y un factor de relajación del mismo orden que con respecto a la lamela media.

\section{BIBLIOGRAFIA}

Bodig, J.; Jayne, B. 1993. Mechanics of wood and wood composites. Krieger, Florida. 712 p.

BS. British Standards Institution. 2003. Structural timber - Strength classes. BS EN 338. London, UK. 14 p.

Diaz-vaz, J.E. 2003. Anatomía de la madera. Marisa Cúneo Ediciones, Chile. 151 p.

Dinwoodie, J.M. 2000.Timber: Its nature and behaviour. E \& FN Spon, London. 257 p.

Entwistle, K.M.; Zadoroshnyj, A. 2008. The recovery of mechano-sorptive creep strains. Journal of Materials Science 43: 967-973

Fischer-Cripps, A. C. 2004. Nanoindentation. Springer-Verlag, New York. USA. 266 p.

Gallegos, B. 2009. Influencia de la temperatura y humedad en tableros para puentes de madera tensados. Memoria de título. Departamento de Ingeniería Civil, Universidad de Concepción. 137 p.

Gindl, W.; Gupta, H.S.; Schöberl, T.; Lichtenegger, H.C.; Fratzl, P. 2004. Mechanical properties of spruce wood cell walls by nanoindentation. Applied Physics, A: Materials Science \& Processing 79(8): 2069-2073

Giuliano, M.; Dechent, P.; Valenzuela, L.; Salgado, M. 2002. Puentes de madera con tableros tensados. $6^{\circ}$ Congreso Internacional ProVial Chile, 5 al 8 de noviembre. $16 \mathrm{p}$.

Guitard, D. 1987. Mécanique du materiau bois et composites. Cepadues-Editions, Francia. 238p. 
Iida, I.; Murase, K.; Isbimaru, Y. 2002. Stress relaxation of wood during the elevating and lowering processes of temperature and the set after relaxation. Journal Wood Science 48(1):8-13

Ishimaru, Y.; Oshima, K.; Iida, I. 2001. Changes in the mechanical properties of wood during a period of moisture conditioning. Journal of Wood Science 47 (4): 254-261

Kainz, J.A.; Ritter, M.A. 1998. Effect of Cold Temperatures on Stress-Laminated Timber Bridges Decks. Proceeding of the 5th World Conference on Timber Engineering, Montreux, Suiza. 2: 42-49.

Montero, C.; Gril, J.; Clair, B. 2010. Interaction between mechanosorptive and viscoelastic response of wood at high humidity level. EPJ Web of Conferences 6: 6p.

Moon, R.; Jakes, J.; Beecher, J.; Frihart, C.; Stone, D. 2009. Relating Nanoindetation to Macroindentation of Wood. Proceedings of the Advanced Biomass Science and Technology for BioBased Products. Hse, CH. Y.; Jiang, Z.; Kuo, M.L. Beijing, China. Capítulo 4, 145-159.

Navi, P.; Pittet, V.; Plummer, C. J. G. 2002. Transient moisture effects on wood creep. Wood Science and Technology 36(6): 447-462.

Navi, P.; Heger, F. 2005. Comportement thermo-hydromécanique du bois: Applications technologiques et dans les structures. Presses polytechniques et universitaires romandes. Lausana, Suiza. 298p.

Quenneville, P.; Van Dalen, K. 1994. Relaxation behaviour of prestressed wood assemblies. Part 1: Experimental study. The Canadian Journal of Civil Engineering 21(5): 736-743.

Ritter, M.A. 1990. Timber Bridges: Design, construction, inspection and maintenance. Washington, DC. $944 p$.

Salmén, L. 1982. Temperature and water induced softening behaviour of wood fiber based materials. PhD. Thesis. The Royal Institute of Technology. Suecia. 150p.

Salmén, L. 2004. Micromechanical understanding of the cell-wall structure. C. R. Biologies 327: 873-880.

Sepúlveda, D.; Bustos, C.; Gacitúa, W.; Dechent, P.; Cloutier, A. 2012. Determinación de un elemento de volumen representativo de probetas de tablero. Maderas. Ciencia y Tecnología 14(3): 339-359

Svensson, S.; Toratti, T. 2002. Mechanical response of wood perpendicular to grain when subjected to changes of humidity. Wood Science and Technology 36(2): 145-156

Toratti, T.; Svensson, S. 2000. Mechano-sorptive experiments perpendicular to grain under tensile and compressive loads. Wood Science and Technology 34(4): 317-326

Ugalde, G. 2004. Diseño y Construcción Tablero de Madera Tensado para el Puente Cautín. Memoria de título. Departamento de Ingeniería Civil, Universidad de Concepción. 183p.

Wanbing, L.; Erickson, R. 1994. The effects of directed diffusion on the mechano-sorptive behavior of small redwood beams. Forest Products Journal 44(1): 8-14 
Wang, S. Y.; Wang, H. L. 1999. Effects of moisture content and specific gravity on static bending properties and hardness of six wood species. Journal of Wood Science 45(2): 127-33

Wolcott, M.; Shutler, E. 2003. Temperature and moisture influence on compression-recovery behavior of wood. Wood and Fiber Science 35(4): 540-51

Wu, Y.; Wang, S.; Zhou, D.; Xing, C.; Zhang, Y. 2009. Use of nanoindentation and silviscan to determine the mechanical properties of 10 hardwood species. Wood and Fiber Science 41(1): 64-73

Zhou, Y.; Fushitani, M.; Kubo, T.; Ozawa, M. 1999. Bending creep behavior of wood under cyclic moisture changes. Journal of Wood Science 45:113-119 